\title{
Co-creation of improved quality in disaster response and recovery
}

\author{
D Clay Whybark ${ }^{1,2}$
}

\author{
Correspondence: \\ Clay_Whybark@unc.edu \\ ${ }^{1}$ Institute for Defense and Business, \\ University of North Carolina, 1250 \\ Environ Way, Chapel Hill, NC, USA \\ ${ }^{2}$ Macon Patton Distinguished \\ Professor of Business (Emeritus), \\ University of North Carolina, Chapel \\ Hill, NC, USA
}

\begin{abstract}
There is a compelling argument that the number and intensity of disasters are increasing and will continue to do so for the foreseeable future. The causes are already evident. They include global climate change, increasing population density, human encroachment into disaster prone areas, recurrent famine, and the increasing intensity of weather events. Similarly, there is a general concern that the quality of the responses to these disasters is decreasing, particularly those causing the most damage. Recent examples include the Ebola epidemic, the Philippian tsunami, Hurricane Sandy, the Tibetan earthquake economic and famine refugee crises, and war-caused refugee situations around the world. Elements of the decrease in response quality include limited global logistics capacity, difficult inter-agency and/or international collaboration, and increased reliance on non-governmental organizations to provide the response. This essay is an appeal for more research on responder co-creation of and quality in the four broad phases of the disaster life cycle: mitigation, preparedness, response, and recovery.

Keywords: Disaster response; Response quality; Co-creation; Research needs
\end{abstract}

\section{Background}

A person needs only to look at a newspaper, listen to a news broadcast, or view the nightly news to learn that the international humanitarian community is now struggling to alleviate human suffering in many parts the world. Indeed millions have been forced to flee from their homes to escape war, harsh regimes, natural disasters and other such events. Some of these people are fortunate enough to be with relatives or friends, more are in refugee camps, and others are trapped in the disaster zone. The organizations that respond to disasters and support these people are severely challenged to provide sufficient resources to meet their needs. The severity of the situation was highlighted recently when, for lack of funds, the United Nations had to halt food distribution to Syrian refugees [1].

The extent of a disaster can range from a local or national flood to a multi-county event like a tsunami or the housing of war refugees. The disaster can come from a variety of causes and the response can require different mixes of skills and supplies. Regardless of the cause or extent of the disaster a response requires resources and the interaction of simultaneous disasters is clearly a factor in resource availability. Moreover, any disaster response can affect the ability to respond effectively to another. The

(c) 2015 Whybark; licensee Springer. This is an Open Access article distributed under the terms of the Creative Commons Attribution License (http://creativecommons.org/licenses/by/4.0), which permits unrestricted use, distribution, and reproduction in any medium, provided the original work is properly credited. 
focus of this paper will be on disasters that require an international response by multiple organizations.

Disasters have been classified into two broad groups: natural and man-made (also called technological disasters) [2]. Interestingly, biological disasters are incorporated in man-made disasters. Examples of natural disasters include the earthquake in Tibet, the Bangladeshi floods, California wildfires, and tsunamis like in the Philippines. Man-made disasters include oil spills like Deepwater Horizon in the Gulf of Mexico, diseases like Ebola in Sierra Leone, industrial accidents like the Bhopal pesticide plant, and wars that create refugees like in Syria. Regardless of category, all of these examples required a resource consuming response adding to the demands on the international humanitarian community.

Statistics on disasters have been gathered since the beginning of the $20^{\text {th }}$ century [3]. The total number of disasters is almost entirely from natural disasters. The number of man-made disasters barely registers on the scales of Figure 1. Overall they only account for $7.5 \%$ of the deaths and 1.7 percent of the damage costs. In addition, the average number of disasters from 1900 to 1959 is only 19 per year and the maximum is only 45 . These also barely register on Figure 1 . There are several other observations about the data depicted in Figure 1. The deaths are frequently correlated with the damage (the intensity), particularly in the recent years. Since the loss of lives seems to be going up as the number of disasters is decreasing, an argument for life-saving effectiveness can be made.

Interestingly the data up through the early 2000s has been used as evidence that the frequency and intensity of disasters have been increasing over time. As shown in Figure 1, the damage costs are still increasing, though the number of disasters per year has declined in the last few years. Nevertheless the forces behind the growth in the number and intensity of disasters are already in place [4]. They include global climate change, increasing population density, human encroachment into disaster prone areas,

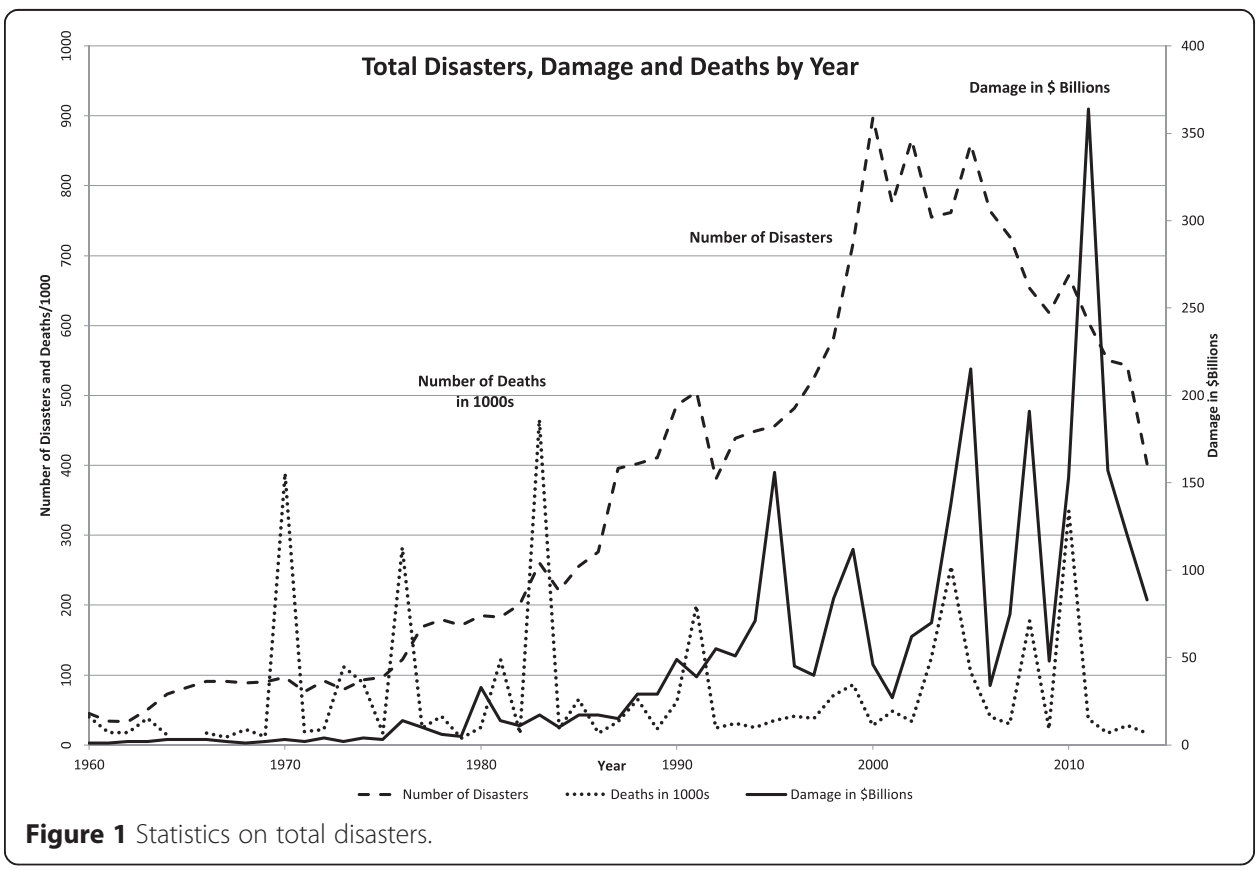


recurrent famine, and the increasing intensity of weather events. Given the capacity limitations of the international humanitarian community that have already been observed, there is concern that the expected increase in demand will require expanded capacity and/or improved efficiency.

The concern about the increases in frequency and intensity has been reinforced in the recent past by concerns about the responses to recent disasters. The recovery in Haiti has been plagued by incomplete payment of pledges, insufficient progress, corruption, and misspent funding [5]. Concerns have been raised about the response to the floods in Pakistan [6] and a there's even a general concern about cooperative purchasing for disaster relief [7]. The response to Hurricane Katrina has received criticism since the storm hit land in the state of Louisiana in the United States. It still is a mixture of the reconstruction and devastation, with some of the new areas being supported by well-known performers [8].

One of the premises of this paper is that these shortfalls in the response to these disasters are indications of poor quality. The "customers" (victims) of the disaster are getting less than the full value of the response. It is not limited to the corruption and graft that is endemic in many of the disaster prone areas of the world. The value shortages stem from poor (or no) pre-planning or other mitigation efforts, inefficient supply chains, poor communication among the responders and other execution issues. These manifestations of quality flaws point to a need for the responders to cocreate quality improvements in their response and reconstruction activities after a disaster.

\section{Literature review}

Concerns about increasing demands for disaster response and limited resources have been expressed by several members of the international humanitarian community [9]. In addition the number and types of organizations responding to disasters has increased since Hurricane Mitch in Central America in 1998, when CNN first covered a disaster live [10]. The media attention also brought private companies, additional non-governmental organizations and even private citizens (including movie stars and famous musicians) into disaster zones [11]. By 2008 the United Nations had developed a formal methodology for private participation in disaster response and had signed a contract with three international logistics companies. The addition of these different organizations brought new resources and capabilities to the responses, but greatly increased coordination requirements [12,13] and the need for better management mechanisms [14].

Researchers have looked at the coordination issues through a variety of lens. Some have a large for-profit business management perspective [15]. Other perspectives include supply chain management [16-18], software applications [19], organizational behavior [20], mathematical modeling [21], case studies [22], and many others. Several researchers, mostly from marketing, have studied the management concept of cocreating value for a company's customers [23]. It has not, however, been widely researched as a tool for increasing the quality of disaster response and recovery. For this paper, increased quality will be the equivalent of providing added value to the victims of a disaster.

Much research has been done on information systems and some addresses co-created emergency information services [24]. Another project co-created 
a 3D visualization of a disaster zone [25]. By emphasizing the "co" aspects (collaboration, cooperation, and coordination) of effective co-creation Sang M. Lee and his colleagues have broadened the scope of the concept [26]. This has helped make cocreation a promising tool to bring to bear on the quality of a response. Of course it still leaves open the question of what is quality in this context.

In the Introduction to this paper, examples are presented of cases where there were, shortfalls in effectiveness during the response to some humanitarian disasters. These shortfalls mean some of the potential value to victims was not realized, thus implying a problem with the quality of the response. Among other things the measurement of the overall quality in humanitarian disaster response and reconstruction is dependent on the nature of the disaster [27]. Some researchers have worked at deriving humanitarian relief chain metrics from commercial supply chain metrics [28]. Others have looked at the personnel attributes (including gender differences) needed for humanitarian logistics [29]. These operational perspectives are essentially efficiency oriented however, and often understate the needs of the overall relief effort.

Further complicating the overall definition of quality is the different perspectives of the various responder organizations that are involved. For a large-scale international event, nothing can begin until the affected country or countries ask for assistance. There may be political objectives behind their permitting only certain country's organizations to be involved in a response. China routinely turns away offered assistance in a disaster and Myanmar was slow to let in aid organizations and wouldn't permit military ships or helicopters to bring in supplies during the cyclone Nargis disaster. There are differences in objectives for other organizations that make overall quality difficult to define. For instance some of the non-governmental organizations have saving lives and health oriented objectives while others may have broad shelter and food metrics. The military may have very different objectives than some of the other government organizations. The media and the public may be looking for exposure while some non-governmental organizations may want exposure to help them raise operating funds.

These different objectives make the development of a single measure of quality difficult. The research to date that has led to fairly comprehensive measures has been largely operational. In general they have to do with speed, cost savings, delivery performance, etc. It is partly because of these different perspectives that the notion of co-creation comes into play. By working together, agreements can be made among the responders and the victims that point the capabilities of the responders to the needs of the victims. Some work has been done already in devising quality measures that are broadly applicable to the organizations that are involved in disaster response [30]. That work was done only for the disaster planning activities, however.

For quite some time, responders have found it useful to define phases of a disaster response for organizing their planning and execution activities. Some academic work has been done on addressing the issues of the overlaps of the phases and ambiguity in assigning some of the activities to phases [31]. Nevertheless, the Federal Emergency Management Agency has defined four phases of emergency: mitigation, preparedness, response, and recovery [32]. There are variations used by some organizations, but these four phases are used by the United Nations and many other disaster response organizations. The four phases as described in Table 1 will be used in this paper to describe opportunities for co-creating quality improvements in disaster response. 
Table 1 The four phases of the disaster life cycle

\begin{tabular}{ll}
\hline The four phases of emergency management & \\
\hline Mitigation & $\begin{array}{l}\text { Includes any activities that prevent an emergency, reduce the } \\
\text { chance of an emergency happening, or reduce the damaging } \\
\text { effects of unavoidable emergencies. }\end{array}$ \\
Preventing future emergencies & $\begin{array}{l}\text { Buying flood and fire insurance for your home is a mitigation } \\
\text { activity. } \\
\text { or minimizing their effects }\end{array}$ \\
Mreparedness & $\begin{array}{l}\text { Includes plans or preparations made to save lives and to help } \\
\text { response and rescue operations. }\end{array}$ \\
Preparing to handle an emergency & $\begin{array}{l}\text { Evacuation plans and stocking food and water are both } \\
\text { examples of preparedness. }\end{array}$ \\
Response & $\begin{array}{l}\text { Preparedness activities take place before an emergency occurs. } \\
\text { Includes actions taken to save lives and prevent further property } \\
\text { damage in an emergency situation. Response is putting your } \\
\text { preparedness plans into action. }\end{array}$ \\
Responding safely to an emergency & Seeking shelter from a tornado or turning off gas valves in an \\
earthquake are both response activities. & Response activities take place during an emergency. \\
Includes actions taken to return to a normal or an even safer \\
Recovery
\end{tabular}

Source: Fema [14] The Four Phases of Emergency Management: (www.training.fema.gov/emiweb/downloads/is10_unit3.doc).

\section{Co-creation opportunities}

The opportunity to increase the quality of disaster response and recovery through cocreation is completely dependent on getting the response organizations together to cocreate solutions. Since each of the four phases of the life cycle has a different mix of personnel and/or organizations it does provide a useful framework for this discussion. In addition, the objectives, time horizons, skill requirements and tools in each phase are quite different, usually requiring a different mix of levels within a given organization. While logistics oriented, Christopher Sandwell provides some insight into different perspectives between organizations and levels in organizations that complicate the communication required for co-creation [33].

\section{Mitigation}

In this phase of the life cycle, the objectives are to reduce the chances of another disaster and the negative consequences if one should happen. Reducing the chances of an occurrence is primarily focused on man-made disasters. The skills required are largely technical and are focused on the reengineering processes to prevent industrial accidents like the Bhopal gas or Fukushima nuclear tragedies. Those same skills are involved in reducing the consequences of disasters by developing early warning systems for typhoons and tsunamis, for example, or improving packaging for critical supplies. In these efforts, the objectives are usually quite clear to all involved, and the test of quality is generally technical performance.

The metrics are not as clear, however for decreasing the negative consequences of the response. This effort is based on reviewing the responses to past disasters. Information and insights from the responders, the planners, the local population, and 
outside experts are needed to improve the response to a recurrence. Because of the variety of skills, organizations, and levels that are involved, this is one of the most obvious areas to employ co-creation. However, the time horizon is not well defined, since some aspects could be on going while others may terminate with the occurrence of another disaster, such as when Hurricane Rita followed Hurricane Katrina within a couple of weeks.

The variety of perspectives that should form the mitigation group is also what makes it difficult to convene and manage. Of course the differences in objectives between individuals and organizations are important to the analysis, but difficult to synthesize into a general quality measure(s). Also since the responders can change from disaster to disaster (even one of the same kind in the same location) it may not be possible to have as broad a representation as desired. Yet previous experience is important to the mitigation effort. Also, involving the local people in the process is important but can be difficult. Some research has been done on incorporating the local point of view [34] but much more is needed.

Some work on developing an integrated approach came out of a case study of the 2004 Indian Ocean tsunami [35]. But more is work needed on methods of organizing and managing the co-creation process with a great diversity of organization, language, skills and motivation involved. The objective would be to improve the process such that the outcome would be one of harmonized goals, shared "ownership," and agreed principles of operation. Desirable as well would be a more integrated measure of quality for the next occurrence of the disaster.

\section{Preparedness}

Preparedness is the phase in which actions are taken in advance of a disaster. There are many areas where disasters occur unpredictably but frequently. Earthquakes in the Andes of South America, Famine in the Sahel of Africa, Cyclones in South East Asia, Hurricanes in the Southeast United States and so forth. In these areas emergency supplies can be prepositioned in anticipation of a disaster, contracts for supplies can be developed, part of the response plan from the mitigation phase can be rolled out, and other actions taken [36]. The objective is one of efficiency when a disaster occurs. There is less concern about the time horizon for these activities, so they are candidates for cocreation of priorities and plans. The participants in the co-creation of these plans have local and expert knowledge; so they can be assembled fairly easily. In fact, considerable research has been done on actions that can be done ahead of time. Some researchers take an inventory perspective [37], others a general operations research perspective [38] and a counter argument has even been raised [39].

There are times when the mitigation work helps greatly with the preparedness. For example, Typhoon Haiyan hit the Philippines in November 2013. It was one of the strongest ever recorded and caused great physical damage and human death and suffering. Mitigation activities started just after the storm hit. Replenishment of supplies and pre-positioning was initiated, disaster plans were gone over, evacuation routes identified and other measures taken. By the time that Typhoon Hagupit hit in December 2014, the early warning system had alerted the authorities. People in the path of the storm were already in shelters and the response team in the field. Fortunately the storm weakened and took a different path that reduced the physical damage, but the mitigation efforts were responsible for the preparedness that greatly reduced the human suffering. 
When there is less of a warning when a disaster occurs there can be little time for co-creation activities. More research is needed on the handoff between the planners and engineers that are engaged in the mitigation effort and those on the ground carrying out the operational work necessary to be prepared. The handoff can be especially difficult if there are multiple locations and languages involved.

\section{Response}

Once the disaster occurs, it is time to monitor the disaster, make modifications in the response plan and roll it out as quickly and safely as possible. This is the time when the respondents get involved. Their overall objective is to respond to get relief to the victims as soon as possible. This is when the co-created plans and objectives will be tested in terms of the improved quality of response. Unfortunately, this is also a part of the life cycle that has very little applied research. In particular, research on the collaboration processes, information access and commonality, and goal alignment procedures would be most helpful.

The disaster area is usually chaotic and communication, cooperation, and collaboration among the responders is usually difficult. The time horizon is related to the length of the disaster, so it is sometimes quite short like some tornadoes, but can be years with refugees. Communication systems have been proposed [40], elements of the planning process have been studied [41], and Jamison Day has provided some hypothesis to be tested [42] but much more research needs to be done. The pressure at the disaster site is to get things done. This makes the task of researching on the scene very difficult. Some work has been done on crowdsourcing at the site. In Haiti for example, crowdsourcing was used to help find open routes and get other information about conditions on the ground [43].

The presence of the media and famous people has created some highly dysfunctional circumstances. Occasionally the media will report on a shipment of wool clothes going to the tropics or inappropriate toys going into a disaster zone. These kinds of often well-intentioned efforts take valuable capacity from the response effort and divert it from more critical uses. In addition, there have been instances of the loss of containers or piles of items that could have been used elsewhere. Here is an opportunity for a cocreated educational campaign for the donors of these unneeded items.

\section{Recovery}

The recovery phase is one in which co-creation is possible and highly desirable. The time horizon is usually quite long and many of the people are on the scene. The response team can help with assessments of what the damage is and what needs to be cleaned up. The local population should have a major say in what gets done for the future and can contribute to the co-creation process. The research on co-creation processes can be helpful here. Some research on planning with teams comprised of "western" responders in African or Asian disasters warn of implicit imposition of the responders' views on the local population [44].

In contrast, one example of recovery with an increase in quality was after the 2004 Indian Ocean tsunami. Not only was the local population of the affected countries involved in co-creating the rebuilding, they coined the phrase "Build Back Better!" The reconstruction effort hewed to that mantra and made the villages safer from future 
disasters, created better schools and achieved many other objectives that gave the local population great pride in their new surroundings [45]. This is not necessarily a model for other recovery efforts but aspects certainly could be.

One difficulty encountered in the rebuilding efforts is the cash flow from donors. There is a tendency for private money to follow the media cycle. Thus the flow dries up when the TV crews leave. The research on this phenomenon is just starting [46]. This is another area where the a co-creation project with the donor community could help educate the donors about the length of the recovery process. For example in 2014 the Ninth Ward in New Orleans still needed much work even though Hurricane Katrina hit in 2005 [47].

The research needs in this phase are more directed to the attempt to "Build Back Better" idea. What is "better" in areas that are prone to disaster, areas such as the Andes in South America or along the seacoast in Asia that tend to be quite conservative? Can research projects be devised that will help those involved in recovery understand better the concerns they face and how to accommodate them? Perhaps co-creation of research agendas would help answer these questions.

\section{Conclusion}

In this paper, data are presented that shows an increasing amount of damage over time from disasters. There is a general concern that both the frequency and intensity of these disasters has been increasing and that the forces for continuing the trend are already in place. Closer inspection shows that there has been a long-term trend (more than 100 years) of increasing damage while, after a period of moderate decline, deaths have shown an increase over the last 25 years or so. The frequency of disasters has dropped over the last 15 years, but increased sharply during the 40 years before that. The conclusion is that frequency, loss of life and damage will continue to increase into the foreseeable future.

At the same time, the capacity to respond to these disasters is already stretched quite thin. This is reflected in many criticisms of the responses to recent disasters around the world. The position of this paper is that these criticisms highlight quality concerns since they indicate reductions from the potential value that can be provided to the victims of the disaster. The disaster life-cycle framework was used to indicate opportunities for co-creation of improved quality disaster responses and recovery. Since disaster response and recovery can join several organizations, countries and companies together in a mutual effort, time spent on co-creation of plans, execution protocols and shared metrics could provide substantial benefits. In addition the entire field of humanitarian relief is under-researched and badly separated by academic field. This is another area for co-creation of value - research value.

Competing interests

The author declares that he has no competing interests.

Received: 13 December 2014 Accepted: 26 February 2015

Published online: 21 May 2015

References

1. The Independent (2014) December 11: UN halts food aid to 1.7 million Syrian refugees after $£ 40 \mathrm{~m}$ funding shortfall: at http://www.independent.co.uk/news/world/middle-east/syrians-face-hungry-winter-as-fundingshortfall-forces-un-to-halt-food-scheme $9896749 . h t m l$ 
2. Below R, Wirtz A, Debarati G-S (2009) Disaster Category Classification and Peril Terminology for Operational Purposes: in Working paper 264 Centre for Research on the Epidemiology of Disasters (CRED) and Munich Reinsurance Company (Munich RE)

3. EM-DAT (2014) The international disaster database: at (http://www.emdat.be/database)

4. IFRC (2014) International Federation of Red Cross and Red Crescent Societies: Types of disasters: definition of hazard: at (http://www.ifrc.org/en/what-we-do/disaster-management/about-disasters/definition-of-hazard/\#)

5. Katz A (2014) Four years later, Haiti's troubled recovery haunts its future: in Time (http://world.time.com/2014/01/ 12/four-years-later-haitis-troubled-recovery-haunts-its-future/)

6. Polastro R, Nagrah A, Steen N, Zafar F (2011) Inter-agency real time evaluation of the humanitarian response to Pakistan's 2010 flood crisis: Madrid: DARA

7. Pazirandeh A, Herlin H (2014) Unfruitful cooperative purchasing: a case of humanitarian purchasing power. J Humanitarian Logist Supply Chain Manag 4(1):24-42

8. The Guardian (2014) New Orleans: houses can be rebuilt, but can trust in central government?: at http:// www.theguardian.com/cities/2014/jan/27/new-orleans-houses-rebuilt-trust-government-hurricane-katrina

9. IFRC (2014) International Federation of Red Cross and Red Crescent Societies: Disaster and crisis management: at (http://www.ifrc.org/en/what-we-do/disaster-management/s

10. Katoch A (2006) The responders' cauldron: the uniqueness of international disaster response: in Journal of International Affairs 59(2)

11. Simo G, Bies AL (2007) The role of nonprofits in disaster response: an expanded model of cross- sector collaboration. Public Adm Rev 67(s1):125-142

12. Bharosa N, Lee J, Janssen M (2010) Challenges and obstacles in sharing and coordinating information during multi-agency disaster response: Propositions from field exercises. Inf Syst Front 12:49-65, online

13. Kapucu N (2009) Interorganizational coordination in complex environments of disasters: The evolution of intergovernmental disaster response systems: in Journal of Homeland Security and Emergency Management 6(1):1547-7355. DOI: 10.2202/1547-7355.1498, July 2009

14. Comfort LK (2007) Crisis management in hindsight: cognition, communication, coordination, and control. Public Adm Rev 67(s1):189-197

15. Tatham $P$, Houghton $L$ (2011) The wicked problem of humanitarian logistics and disaster relief aid. J Humanitarian Logistics Supply Chain Manag 1(1):15-31

16. Boin A, Kelle P, Whybark DC (2010) Resilient supply chains for extreme situations: outlining a new field of study. Spec Issue Int J Prod Econ 126(1):1-6

17. Day JM, Melnyk SA, Larson PD, Davis EW, Whybark DC (2012) Humanitarian and disaster relief supply chains: a matter of life and death. J Supply Chain Manag 48(2):21-36

18. Van Wassenhove LN (2006) Humanitarian aid logistics: supply chain management in high gear. J Oper Res Soc 57(5):475-489.

19. Luqman F, Griss M (2010) Overseer: a mobile context-aware collaboration and task management system for disaster response. In: IEEE Eighth International Conference on Creating Connecting and Collaborating through Computing (C5)., pp 76-82

20. Harrald JR (2006) Agility and discipline: critical success factors for disaster response. Ann Am Acad Pol Soc Sci 604(1):256-272

21. Yi W, Özdamar $L$ (2007) A dynamic logistics coordination model for evacuation and support in disaster response activities. Eur J Oper Res 179(3):1177-1193

22. Akhtar P, Marr MR, Garnevska EV (2012) Coordination in humanitarian relief chains: chain coordinators. J Humanitarian Logistics Supply Chain Manag 2(1):85-103

23. Prahalad CK, Ramaswamy V (2004) Co-creation experiences: the next practice in value creation. J Interact Market 18(3):5-14

24. Zhiyi Wang, Hamalainen M, Lin Z (2008) An open community approach to emergency information services during a disaster: in Information Science and Engineering, ISISE '08. International Symp IEEE 1:649,654.

25. Siau K, Nah FFH, Mennecke BE, Schiller SZ (2010) Co-creation and collaboration in a virtual world: a 3d visualization design project in second life. J Database Manag 21(4):1-13

26. Lee SM, Olson DL, Trimi S (2012) Co-innovation: convergenomics, collaboration, and co-creation for organizational values. Manag Decis 50(5):817-831

27. Brown DE, Robinson CD (2005) Development of metrics to evaluate effectiveness of emergency response operations: at (http://www.dtic.mil/get-tr-doc/pdf?Location=U2\&doc=GetTRDoc.pdf\&AD=ADA464028)

28. Beamon BM, Balcik B (2008) Performance measurement in humanitarian relief chains. Int J Public Sect Manag 21(1):4-25

29. Kovács G, Tatham P (2009) Humanitarian logistics performance in the light of gender. Int J Prod Perform Manag 58(2):174-187

30. Alexander D (2005) Towards the development of a standard in emergency planning. Disast Prev Manag Int J 14(2):158-175

31. Neal DM (1997) Reconsidering the Phases of Disasters. Int J Mass Emerg Disast 15(2):239-264

32. FEMA (2014) The four phases of emergency management: at (http://www.training.fema.gov/emiweb/downloads/ is10_unit3.do)

33. Sandwell C (2011) A qualitative study exploring the challenges of humanitarian organisations. J Humanitarian Logistics Supply Chain Manag 1(2):132-150

34. Perry RW (2003) Incident management systems in disaster management: in. Disast Prev Manag Int J 12(5):405-412

35. Moe TL, Pathranarakul P (2006) An integrated approach to natural disaster management: public project management and its critical success factors. Disast Prev Manag Int J 15(3):396-413

36. Sheppard A, Tatham P, Fisher R, Gapp R (2013) Humanitarian logistics: enhancing the engagement of local populations. J Humanitarian Logistics Supply Chain Manag 3(1):22-36 
37. Duran S, Gutierrez MA, Keskinocak P (2011) Pre-positioning of emergency items for CARE international. Interfaces 41(3):223-237, Online

38. Caunhye AM, Nie X, Pokharel S (2012) Optimization models in emergency logistics: a literature review. Socioecon Plann Sci 46(1):4-13

39. Kunz N, Reiner G, Gold S (2014) Investing in disaster management capabilities versus pre-positioning inventory: a new approach to disaster preparedness. Int J Prod Econ 157:261-272

40. Turoff M, Chumer M, de Walle BV, Yao X (2004) The design of a dynamic emergency response management information system (DERMIS). J Inform Technol Theory Appl (JITA) 5(4):1-35

41. McConnell A, Drennan L (2006) Mission impossible? planning and preparing for crisis. J Contingencies Crisis Manag 14(2):59-70

42. Day JM (2014) Fostering emergent resilience: the complex adaptive supply network of disaster relief. Int J Prod Res 52(7):1970-1988

43. Zook M, Graham M, Shelton T, Gorman S (2010) Volunteered geographic information and crowdsourcing disaster relief: a case study of the Haitian earthquake. World Med Health Pol 2:7-33

44. Smirl L (2008) Building the other, constructing ourselves: spatial dimensions of international humanitarian response. Int Pol Sociol 2(3):236-253

45. Kennedy J, Ashmore J, Babister E, Kelman I (2008) The meaning of "Build Back Better": evidence from post-tsunami Aceh and Sri Lanka. J Contingencies Crisis Manag 16(1):24-36

46. Foundation Center and Center for Disaster Philanthropy (2014) Measuring the state of disaster philanthropy 2014 data to drive decisions: at http://www.foundationcenter.org/gainknowledge/research/pdf/ disasterphilanthropy_2014.pdf

47. Los Angeles Times (2014) January 19 Still marked by Hurricane Katrina: at http://articles.latimes.com/2014/jan/19/ nation/la-na-lower-ninth-ward-20140119

Submit your manuscript to a SpringerOpen ${ }^{\circ}$ journal and benefit from:

- Convenient online submission

- Rigorous peer review

- Immediate publication on acceptance

- Open access: articles freely available online

- High visibility within the field

- Retaining the copyright to your article

Submit your next manuscript at $\gg$ springeropen.com 